\title{
ТРАНСФОРМАЦИЯ ПАССИВНОГО ИЗБИРАТЕЛЬНОГО ПРАВА В РОССИИ ПОСЛЕ АКЦИЙ ПРОТЕСТА «ЗА ЧЕСТНЫЕ ВЫБОРЫ» 2012 ГОДА
}

Аннотация: В статье рассматривается трансформация пассивного избирательного права в России после акиий протеста «За честные выборы». Отмечается, что трансформация пассивного избирательного права сохранила централизаторский вектор, имитировав демократизацию избирательной системы. Анализ законодательства и политической практики свидетельствуют, что ограничения пассивного избирательного права граждан РФ противоречат нормам международного права и Конституц̧ии РФ, в области политической практики расходятся с сущңностными принцииами избирательного права, в частности невмешательства государства в избирательньй прочесс, равенства участников выборов. В статье использовались историко-материалистический, формально-юридический, соииологический методь исследования и подходы. Исследование осуществлено в проблемно-праксиологическом ключе. Массовые акции протеста 2011-2012 годов качественно не изменили возможности граждан быть избранными в представительнье органы государственной власти иместного самоуправления и были сопровождень дополнительными ограничениями, имеютими важное значение в области селективных функций государства. Избирательная система России продолжила трансформацию в направлении интересов федерального президента и высшей государственной бюрократии, что ведет к разрушению системы обратных связей, деградации российской политии и имитационности пассивного избирательного права.

Ключевые слова: Пассивное избирательное право, централизация, авторитаризм, президентализм, делегативная демократия, выборы, представительная демократия, ограничение прав, конституционализм, демократия. Abstract: This article examines the transformation of the passive electoral right within the Russian Federation after the acts of protest "For Fair Elections". The author highlights that the transformation of this right retained its centralized vector, imitating the democratization of the electoral system. The analysis of the legislation and the political practice demonstrates that the limitations of the Russian citizens' passive electoral right contradicts the norms of international law and the Constitution of the Russian Federation; in the area of political practice they infringe upon the essential principles of electoral right, including government non-involvement into the electoral process and equality of the voters. The mass protests of 2011-2012 did not produce changes, nor gave the citizens the opportunity to be elected as officials of the branches of government, and were further restricted by additional limitations that have a significant impact in the area of the selective functions of the government. The electoral system of the Russian Federation continued the transformation in the direction of interests of the federal president and the highest government bureaucracy, which leads to a collapse of the feedback system, degradation of Russian politeia, and imitation of the right to be elected.

Keywords: Representative democracy, elections, delegative democracy, presidentialism, authoritarianism, centralization, passive electoral right, limitation of rights, constitutionalism, democracy.

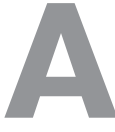

кции протеста «За честные выборы», прошедшие в крупных городах России привели к трансформации пассивного избирательного права, затронув все уровни функционирования российской политии. Явившись уступкой «внесистемной» оппозиции и гражданским активистам, избирательные новации были призваны смягчить давление на государство и обеспечить сохранность существующей системы.

В мае 2012 года был принят федеральный закон «О внесении изменений в отдельные законодательные акты Российской Федерации в связи с освобождением политических партий от сбора подписей избирателей на выборах депутатов Государственной Думы Федерального Собрания Российской Федерации, в органы государственной власти субъектов Российской Федерации и органы местного самоуправления» [1], реализовавший идею Президента
РФ, озвученную в Послании Федеральному Собранию 22 декабря 2011 года - сократить количество подписей избирателей с 2 миллионов до 300 тысяч для кандидатов, выдвигаемых путем самовыдвижения, а для кандидатов от непарламентских партий - до 100 тысяч подписей.

4 декабря 2012 года В.В. Путин подписал новый Федеральный закон «О порядке формирования Совета Федерации Федерального Собрания Российской Федерации» [2], который не изменил механизма косвенных выборов членов Совета Федерации от региональных парламентов, но использовал идею выборов членов Совета Федерации от главы субъекта РФ: глава субъекта Федерации при регистрации в избирательной комиссии субъекта РФ, направляет в «верхнюю» палату Федерального Собрания РФ три кандидатуры члена Совета Федерации ФС РФ, одна из которых в дальнейшем 


\section{Право и политика 4 (184) 2015}

и будет назначена им в случае его избрания. Сведения о выдвигаемых главой исполнительной ветви власти субъекта РФ кандидатах в члены Совета Федерации размещают в помещениях для голосования на выборах, что позволило провести параллель с институтом выборов.

В соответствии с новым законом «О выборах депутатов Государственной Думы Федерального Собрания Российской Федерации» от 22 февраля 2014 года [3] пропорциональная система выборов депутатов «нижней» палаты российского парламента была заменена пропорционально-мажоритарной избирательной системой - 225 депутатов избираются по одномандатным избирательным округам (один округ - один депутат), и 225 депутатов избираются по федеральному избирательному округу пропорционально числу голосов избирателей, поданных за федеральные списки кандидатов в депутаты Государственной Думы. Изменение избирательной системы с пропорциональной на смешанную систему расширило политические права российских граждан, предоставив им возможности для самовыдвижения. Кроме того, был снижен избирательный барьер с 7 до 5 процентов для политических партий, а Ф3-41 от 02.05.2012 все политические партии были освобождены от сбора подписей в «нижнюю» палату российского парламента и региональные легислатуры.

Протестное движение заставило государство изменить механизм фактического назначения глав исполнительной ветви власти субъекта РФ на «всенародное избрание». В соответствии с принятым 2 мая 2012 года Ф3-40 право на выдвижение кандидата на должность высшего должностного лица субъекта Федерации (руководителя высшего исполнительного органа государственной власти субъекта РФ) получили политические партии, а также граждане (путем самовыдвижения) [4].

Вслед за установлением смешанной системы выборов в Государственную Думу РФ, смешанные системы начали устанавливаться при формировании региональных парламентов, ряд из которых избирался исключительно с помощью пропорциональной системы выборов. Негласной директивой этому процессу послужили изменения в ФЗ «Об общих принципах организации законодательных (представительных) и исполнительных органов государственной власти субъектов Российской Федерации» от 2 ноября 2013 года [5], устанавливающие новое соотношение числа депутатов законодательного (представительного) органа государственной власти субъекта РФ, избираемых по пропорциональной и мажоритарной избирательным системам - число депутатов избираемых по пропорциональной системе было снижено с 50 процентов до
25 процентов. Пропорциональная избирательная система была изменена на смешанную в Амурской области и Ямало-ненецком автономном округе. При этом в Московской области переход на смешанную систему выборов был осуществлен уже в 2011 году.

Массовые акции протеста после избирательного цикла 2011-2012 годов привели также к частичному отказу от института сити-менеджера, а сам институт сити-менеджера получил отрицательную оценку Министерства регионального развития [6]. Были возвращены прямые выборы глав муниципальных образований в Благовещенске, Верхнем Тагиле, Волгограде, Екатеринбурге, Заречном, Миассе, Ульяновске и других городах; а в Иркутской области был принят региональный закон о местном самоуправлении, устанавливающий прямые выборы глав и депутатов во всех муниципалитетах [7].

Вместе с тем, анализ правовой и политической практики свидетельствует о том, трансформация пассивного избирательного права в известной мере носит имитационный характер и сохраняет возможности государства влиять на избирательный процесс. Нормы российского избирательного законодательства продолжают противоречить нормам международного права, в частности ограничения на участие в выборах граждан Российской Федерации, имеющих гражданство другого государства; сохраняются неравные требования регистрации кандидатов от политических партий на выборах Президента РФ, а законодательство продолжает сохранять неюридическую терминологию, например использование понятия «безупречная репутация», фигурирующее при выборах членов Совета Федерации.

Регистрация кандидатов в Президенты РФ ставит политические партии имеющие представительство в «нижней» палате федерального парламента не в равные условия с другими политическими силами. Таким образом, продолжается нарушаться принцип равенства участников избирательного процесса.

В кратологической парадигме, размещение списков членов Совета Федерации на избирательном участке создает лишь иллюзию прямых выборов и не имеет политического значения, а предварительное выдвижение кандидатур в Совет Федерации повышает зависимость региональных глав исполнительной власти от заинтересованных сторон, в первую очередь, Администрации Президента РФ, предоставляя последним большие возможности для управления избирательным процессом. Учитывая высокую степень централизации российской политии, главы регионов становятся инструментами формирования федеральной элиты, а их политическое будущее оказывается в зависимости от политических 
акторов, способных реально влиять на избирательный процесс в регионах. Кроме того, использование идеи о формировании Совета Федерации ФС РФ «на основе волеизъявления избирателей» подрывает позитивное отношение население к прямым выборам как к более демократическому механизму формирования «верхних» палат, используемого в США, Мексике, Бразилии, Польше, Чехии, Румынии и других демократических стран.

Выборы глав исполнительной власти субъектов РФ сопровождаются серьезными ограничениями, нивелирующими пассивное избирательное право граждан и позволяющими государству вести селекцию кандидатов. Так, постпротестное законодательство вводит систему избирательных «фильтров»: после выдвижения, кандидат на должность главы региона должен получить поддержку от 5 \% до 10 \% (обычно 7 \%) депутатов представительных органов муниципальных образований и (или) избранных на муниципальных выборах глав муниципальных образований субъекта Федерации. При этом кандидат должен быть поддержан указанными лицами не менее чем в трех четвертях муниципальных районов и городских округов субъекта Федерации или внутригородских округов - применительно к городам федерального значения. Подписи муниципальных депутатов в поддержку кандидата на должность главы субъекта Федерации должны иметь нотариальное удостоверение («нотариальный фильтр»). Как отмечается в докладе «Прямые выборы губернаторов и система сбора муниципальных подписей в 2012 г.: влияние на развитие политической системы и направления совершенствования», подготовленном Институтом социально-экономических и политических исследований «... фильтр выгоден федеральной и региональной власти как механизм отсечения нежелательных кандидатов, что может влиять на практику его применения» [8, с. 9].

Так называемые муниципальный и нотариальный «фильтры» являются одними из дискриминационных в механизме выдвижения кандидата на должность главы субъекта РФ. Именно они ограничивают возможности для развития региональных политических систем, позволяя действующим руководителям регионов полностью контролировать избирательный процесс.

Кроме преодоления муниципального и нотариального «фильтров» кандидаты, выдвигаемые путём самовыдвижения обязаны собрать подписи избирателей в количестве от 0,5 до 2 процентов. Процент подписей устанавливается региональным законодательством и, как правило, он максимальный. Условие сбора подписей избирателей после прохождения муниципального «фильтра» ставит кандидатов самовыдвиженцев в неравные условия с «партийными» кандидатами, что также является дискриминационным механизмом, призванным не допустить регистрацию менее зависимых от государства кандидатов. Следует обратить внимание на то, что на выборах 14 сентября 2014 года в главы субъектов РФ было выдвинуто 207 кандидатов - 204 кандидата от 42 политических партий и только 3 кандидата в порядке самовыдвижения; в избирательные бюллетени были внесены фамилии 135 партийных кандидатов от 24 политических партий и только 2 кандидатов, выдвинутых в порядке самовыдвижения [9].

Постпротестным законодательством было предусмотрено и право кандидата на должность главы субъекта РФ, осуществляющего ранее данные полномочия не менее одного года, если выборы назначены в связи с досрочным прекращением им своих обязанностей по собственному желанию, получать согласие Президента РФ на выдвижение, что обеспечило им соответствующие преимущества и усилило их лояльность по отношению к главе государства. Однако основной «инновацией» стала возможность Президента РФ по своей инициативе проводить консультации с политическими партиями, выдвигающими кандидатов на должность высшего должностного лица субъекта Федерации, а также с кандидатами, выдвинутыми на указанную должность в порядке самовыдвижения. Порядок проведения таких консультаций был предоставлен Президенту РФ. Следует согласиться с И.Л. Ландау, что « ... право проведения консультаций с политическими партиями, выдвигающими кандидатов, а также с кандидатами, выдвинутыми в порядке самовыдвижения, выходит за пределы его (Президента РФ - авт.). Данное полномочие позволяет Президенту РФ вмешиваться во внутрипартийные дела; кроме того, неопределенность содержания самого института консультаций создает возможность для его произвольного применения» [10 , с. 31].

Ф3-№ 303, установивший новое соотношение числа депутатов законодательного (представительного) органа государственной власти субъекта РФ, избираемых по пропорциональной и мажоритарной избирательным системам, исключил распространение данной нормы на выборы депутатов законодательных (представительных) органов государственной власти городов федерального значения Москвы и Санкт-Петербурга - крупнейших субъектов РФ. В республиках Дагестан, Ингушетия, Кабардино-Балкарской Республике, Республике Калмыкия, Чеченской Республике; в Калужской, Тульской областях, Санкт-Петербурге продолжает сохраняться полностью пропорциональная система выборов, подвергаемая критике со стороны 
DOI: $10.7256 / 1811-9018.2015 .4 .14705$

При цитировании этой статьи сноска на доі обязательна

\section{Право и политика 4 (184) 2015}

политологов [11] и, по словам К. Поппера, противоречащая демократии [12]. Пропорциональная избирательная система консервирует процесс трансформации регионального политического пространства, способствуя консолидации элитных группировок, оттесняя от участия в реализации пассивного избирательного права других участников и предоставляя широкие возможности для управления группам, вышестоящим на лестнице административного ресурса.

Возврат к прямым выборам глав муниципальных образований остается малоэффективным, в силу нарушения основополагающих принципов выборов, в частности невмешательства государства в избирательный процесс. С известной долей условности об этом, могут свидетельствовать результаты выборов глав муниципальных образований - административных центров субъектов Российской Федерации 14 сентября 2014 года. Во всех муниципальных образованиях - административных центрах субъектов Российской Федерации победу одержали кандидаты, поддерживаемые главами регионов. В Амурской области на выборах мэра города Благовещенска, победу одержал А.А. Козлов (38,68 \%) [13]; в Сахалине - С.А. Надсадин (79,40 \%) [14]; в Анадыре - И.В. Давыденко (83,08\%) [15].

Схожая ситуации обнаруживается при анализе результатов выборов 14 сентября 2014 года в представительные органы муниципальных образований - административных центров субъектов Российской Федерации. Во всех 21-м муниципальном образовании - административных центрах субъектов Российской Федерации победу одержали представители партии «Единая Россия». В среднем представители «Единой России» получили в данных представительных органах около 70 процентов депутатских мандатов. Наиболее результативными для «Единой России» оказались выборы в Салехарде, Хабаровске и Пензе. В данных муниципальных образованиях партия получила более 90 процентов депутатских мандатов.

Кроме того, «либерализация» законодательства, затрагивающая пассивное избирательное право сопровождалась установлением новых ограничений, в частности был введен запрет реализации гражданам пассивного избирательного права после погашения им судимости при совершении тяжкого преступления данный срок был определен 10 годами, особо тяжкого - 15 годами после снятия судимости, что не только противоречит статье 86 УК РФ, но и содержит ярко выраженную политическую составляющую. Учитывая, что тяжким и особо тяжким преступлениям в России относятся, в том числе, преступления экстремистской направленности, а понятие «экстремизм» в сверх политизированной российской политической системе носит неюридический характер, то ограничение пассивного избирательного права в отношении лиц, рассматриваемых в качестве «экстремистов», может свидетельствовать о возросшей селективной роле государства в избирательном процессе.

Федеральным законом от 2 мая 2012 г. № 40-Ф3 был установлен запрет на выдвижение главами субъектов РФ, отрешенными от должности главой государства в течение 2 лет, исчисляемых со дня вступления в силу указа Президента Российской Федерации об отрешении его от должности и до дня назначения выборов высшего должностного лица субъекта Российской Федерации выдвигать свою кандидатуру на указанную должность в каком-либо субъекте Федерации, что лишило данную категорию лиц, возможности подтвердить/ опровергнуть легитимность решения главы государства с помощью выборов. При этом, если отставка главы исполнительных органов власти региона произошла на основании недоверия выраженного региональным парламентом, то президент получил право дачи согласия экс-главе субъекта, исполнявшему полномочия не менее 1 года выдвинуться на указанную должность.

Негативной тенденцией в сфере реализации гражданами РФ пассивного избирательного права стал подписанный 3 февраля 2015 года Президентом РФ Федеральный закон «О внесении изменений в статьи 32 и 33 Федерального закона «Об основных гарантиях избирательных прав и права на участие в референдуме граждан Российской Федерации» и Федеральный закон «Об общих принципах организации местного самоуправления в Российской Федерации» [16]. Закон вводит процедуру назначения мэров и глав районов, действующую при назначении сити-менеджеров и фактически лишающую граждан быть избранными на данные должности. Кроме того, данными поправками вводится также возможность назначения мэра или главы района из состава муниципальных депутатов. Очевидно, это данные инновации ограничивают пассивное избирательное право граждан, предполагают усиление политического влияния губернаторов и президентов республик на местное самоуправление и предупреждение ситуаций, произошедших в Екатеринбурге и Петрозаводске, где мэрами были избраны представители оппозиции Е.В. Ройзман и Г.И. Ширшина.

Трансформация пассивного избирательного права в России после акций протеста «За честные выборы» 2012 года сохранила стремление правящего российского истеблишмента оградить граждан от участия в управлении государством. Сохраняющаяся автократическая тенденция ведёт к деградации российской политии, ослаблению системы обратной связи и возникновению массовых фрустраций. 


\section{Библиография:}

1. О внесении изменений в отдельные законодательные акты Российской Федерации в связи с освобождением политических партий от сбора подписей избирателей на выборах депутатов Государственной Думы Федерального Собрания Российской Федерации, в органы государственной власти субъектов Российской Федерации и органы местного самоуправления: Федеральный закон от 02.05.2012 41-Ф3 (с изм. от 22.02.2014) // Собрание законодательства РФ, 07.05.2012, № 19, ст. 2275.

2. О порядке формирования Совета Федерации Федерального Собрания Российской Федерации: Федеральный закон от 3 декабря 2012 г. № 229-Ф3. [Электронный ресурс] // URL: http://www.garant.ru/products/ipo/prime/doc/70171674/ (дата обращения: 25.02.2015).

3. О выборах депутатов Государственной Думы Федерального Собрания Российской Федерации: Федеральный закон № 20-Ф3 от 22.02.2014 (ред. от 24.11.2014) // Собрание законодательства РФ, 24.02.2014, № 8, ст. 740.

4. О внесении изменений в Федеральный закон «Об общих принципах организации законодательных (представительных) и исполнительных органов государственной власти субъектов Российской Федерации» и Федеральный закон «Об основных гарантиях избирательных прав и права на участие в референдуме граждан Российской Федерации»: Федеральный закон Российской Федерации от 2 мая 2012 г. - № 40-Ф3 //Российская газета - Федеральный выпуск от 4 мая 2012, - № 5772 .

5. О внесении изменений в отдельные законодательные акты Российской Федерации: Федеральный закон № 303-Ф3 от 2 ноября 2013 г. // Собрании законодательства Российской Федерации от 4 ноября 2013 г. № 44 ст. 5642.

6. Назначены неэффективными. Минрегион против дальнейшего распространения института сити-менеджеров. [Электронный pecypc] // URL: http:/www.gazeta.ru/politics/2011/07/22_a_3703137.shtml (дата обращения: 25.02.2015)

7. Об отдельных вопросах формирования органов местного самоуправления муниципальных образований Иркутской области: Закон Иркутской области от 30.05.2014 № 11/5a - 3С.

8. Прямые выборы губернаторов и система сбора муниципальных подписей в 2012 г.: влияние на развитие политической системы и направления совершенствования: Аналитический доклад Фонда «Институт социально-экономических и политических исследований»,-Москва, ноябрь 2012 г. - 84 с.

9. Выборы-2014-Единый день голосования. [Электронный ресурс] // URL: http://azerros.ru/events-and-comments/20118-vybory2014-edinyy-den-golosovaniya.html (дата обращения: 02.11.2014).

10. Ландау И.Л. Выборы губернатора: Анализ федерального и регионального законодательства // Вестник Балтийского государственного университета им. И. Канта, 2013,-Вып. 9 . С. 30-36.

11. Кынев А.В. Пропорциональная избирательная система по-российски: ограниченная конкуренция и управляемая партийность // Российское электоральное обозрение, 2007. - № 1. - С. 30-40.

12. Поппер К. Пропорциональная система противоречит демократии. [Электронный ресурc] // URL: http://www.democracy. ru/curious/democracy/Popper_democracy.html (дата обращения: 25.02.2015)

13. Официальный сайт Избирательной комиссии Амурской области. Выборы мэра г. Благовещенска. [Электронный pecypc] // URL: http://www.amur.vybory.izbirkom.ru/region/region/amur?action=show\&root=1\&tvd=4284003263710\&vr $\mathrm{n}=4284003263706 \AA$ ion=28\&global=\&sub_region=28\&prver=0\&pronetvd=null\&vibid=4284003263710\&type=234. (дата обращения: 25.02.2015)

14. Предварительные итоги голосования http://izbirkom.admsakhalin.ru/itogi_m_18/; Официальный сайт Избирательной комиссии Сахалинской области. В Сахалинской области состоялись муниципальные выборы. [Электронный ресурс] // URL: http://sakhalin.izbirkom.ru/isp/sx/art/963824/cp/1/br/929994.html (дата обращения: 25.02.2015)

15. Официальный сайт Избирательной комиссии Чукотского автономного округа. Выборы в органы местного самоуправления Чукотского автономного округа 2014 года. [Электронный ресурс] // URL: http://chukot.izbirkom.ru/isp/sx/art/950466/ cp/1/br/929124.html (дата обращения: 25.02.2015)

16. О внесении изменений в статьи 32 и 33 Федерального закона «Об основных гарантиях избирательных прав и права на участие в референдуме граждан Российской Федерации» и Федеральный закон «Об общих принципах организации местного самоуправления в Российской Федерации»: Федеральный закон от 03.02.2015 № 8-Ф3// Собрание законодательства РФ, 09.02.2015, № 6, ст. 886

17. Н. М. Добрынин Размышления о проблемах становления правового государства в России. // Право и политика. - 2012. - 2. - С. $232-242$.

18. Кочетков В.В. Русские ценности и российская Конституция 1993 года // Право и политика. - 2013. - 13. - С. 1855 - 1865. DOI: 10.7256/1811-9018.2013.13.9736.

19. М. Б. Бекбосынов Местное самоуправление в условиях федеративной России: законодательное обеспечение, проблемы и перспективы // Право и политика. - 2012. - 1. - С. 16 - 22.

20. Зворыгина М.А. Российский федерализм и зарубежный опыт консоциальной демократии // Тренды и управление. - 2014. - 1. - C. 14 - 20. DOI: 10.7256/2307-9118.2014.1.12384.

21. Жолобова О.А. Основные механизмы формирования стратегии региональной политики в современной России // Тренды и управление. - 2014. - 2. - С. 168 - 174. DOI: 10.7256/2307-9118.2014.2.12405.

22. В. Е. Чуров, Б.С. Эбзеев Демократия и управление избирательным процессом: отечественная модель // Журнал зарубежного законодательства и сравнительного правоведения / Journal of foreighn legislation and comparative law. - 2011. - 3. - C. 24 - 35. 
DOI: $10.7256 / 1811-9018.2015 .4 .14705$

При цитировании этой статьи сноска на dоі обязательна

\section{Право и политика 4 (184) 2015}

\section{References (transliterated):}

1. Landau I.L. Vybory gubernatora: Analiz federal'nogo i regional'nogo zakonodatel'stva // Vestnik Baltiiskogo gosudarstvennogo universiteta im. I. Kanta, 2013, - Vyp. 9. S. 30-36.

2. Kynev A.V. Proportsional'naya izbiratel'naya sistema po-rossiiski: ogranichennaya konkurentsiya i upravlyaemaya partiinost' // Rossiiskoe elektoral'noe obozrenie, 2007. - № 1. - S. 30-40.

3. Popper K. Proportsional'naya sistema protivorechit demokratii. [Elektronnyi resurs] // URL: http://www.democracy.ru/curious/ democracy/Popper_democracy.html (data obrashcheniya: 25.02.2015)

4. N. M. Dobrynin Razmyshleniya o problemakh stanovleniya pravovogo gosudarstva v Rossii. // Pravo i politika. - 2012 . - 2. - C. $232-242$.

5. Kochetkov V.V. Russkie tsennosti i rossiiskaya Konstitutsiya 1993 goda // Pravo i politika. - 2013. - 13. - C. 1855 - 1865. DOI: 10.7256/1811-9018.2013.13.9736.

6. M. B. Bekbosynov Mestnoe samoupravlenie v usloviyakh federativnoi Rossii: zakonodatel'noe obespechenie, problemy i perspektivy // Pravo i politika. - 2012. - 1. - C. $16-22$.

7. Zvorygina M.A. Rossiiskii federalizm i zarubezhnyi opyt konsotsial'noi demokratii // Trendy i upravlenie. - 2014. - 1. - C. 14 20. DOI: $10.7256 / 2307-9118.2014 .1 .12384$.

8. Zholobova O.A. Osnovnye mekhanizmy formirovaniya strategii regional'noi politiki v sovremennoi Rossii // Trendy i upravlenie. - 2014. - 2. - C. 168 - 174. DOI: 10.7256/2307-9118.2014.2.12405.

9. V. E. Churov, B.S. Ebzeev Demokratiya i upravlenie izbiratel'nym protsessom: otechestvennaya model' // Zhurnal zarubezhnogo zakonodatel'stva i sravnitel'nogo pravovedeniya / Journal of foreighn legislation and comparative law. - 2011. - 3. - C. $24-35$. 